\title{
FORIE SÃO JOÃO E FORTALZZA DE SANTO AMARO DA BARRA GRANDE: GUARDIÕES DA NOSSA IDENTIDADE CULTURAL
}

\author{
Adriana Sanajotti Nakamuta \\ anakamuta@yahoo.com.br
}

Esta pesquisa é decorrente das reflexões geradas durante a graduação em Artes Plásticas na Faculdade de Artes, Filosofia e Ciências Sociais da Universidade Federal de Uberlândia e do projeto de pesquisa desenvolvido em 2003 e 2004 junto ao NUPAV (Núcleo de Pesquisa em Artes Visuais) com o apoio do PIBIC (Programa Institucional de Bolsas de Iniciação Científica - $\mathrm{CNPq}$ ) sob a orientação da Dra. Yacy Ara Froner, que teve como objetivo o levantamento das construções fortificadas no litoral paulista brasileiro bem como uma síntese histórica e tipológica atual dos monumentos encontrados e registrados por meio de visitas locais.

O levantamento foi executado no mês de fevereiro de 2004 pelo litoral norte e baixada santista do Estado de São Paulo passando pelas seguintes cidades (em ordem visitada) Ubatuba, Caraguatatuba, São Sebastião, Ilhabela, Bertioga, Guarujá, Santos e Praia Grande, para a localização geográfica e o registro fotográfico das construções encontradas ou possíveis vestígios, assim como documentos que foram encontrados nos arquivos locais, bibliotecas e outras instituições verificando a política de uso atual e a inserção desses patrimônios na sociedade por meio da informação, conhecimento e como meio de extroversão.

O objetivo primordial de defender as terras de possíveis invasores e de outros colonizadores gerou a construção das fortalezas que pontuaram definitivamente a efetivação dos lusitanos em nossas terras bem como registraram para História da Arte no Brasil marcos para a transmissão dos conhecimentos e da cultura européia.

O Forte São João (1532) e a Fortaleza de Santo Amaro da Barra Grande (1584) compõem o objetivo deste trabalho para uma breve discussão sobre pontos que considero instigante e importante para História da Arte no Brasil diante dos fatos históricos e conseqüentemente seus desdobramentos tipológicos. Investigar esses monumentos foi pontuar fatos históricos importantes que se entrelaçam aos percursos que a arte colonial brasileira assumiu.

\section{Pesquisa de campo}

Como citado anteriormente apresentarei o resultado da pesquisa de acordo com a seqüência das cidades percorridas. Em Ubatuba encontrei dois canhões que defendiam o porto da cidade no século XIX, este de grande importância para o escoamento das riquezas produzidas no planalto - do Vale o Porto de Ubatuba o mais 
importante corredor de exportação. Com tamanha importância é impossível não pensar que a cidade não abrigou nenhuma construção fortificada nas imediações, porém como não foram encontrados vestígios ou mesmo documento que possa esclarecer estes questionamentos, não cabe neste momento uma minuciosa investigação para suprir estas suposições.

Em São Sebastião e Ilhabela são marcadas principalmente pela efervescência com o cultivo de roças para a subsistência a partir do século XVII. Contudo, por possuir atividades dispersas ao longo do canal, é desconsiderado pela política de defesa estratégica das fortificações até o final do século XVIII. Com o "Contrato de Baleias" (monopólio real), o comércio ganhou impulso na região e foi sendo levantada uma Armação na Ilha de São Sebastião - hoje Ilhabela - em meados do século XVIII. Essa crescente importância econômica da região despertou interesse das autoridades, e em 1767 o general Morgado de Mateus - governador da Capitania de São Paulo - já expressava sua preocupação com a proteção do canal. Em 1770, iniciaram-se as obras do Forte da Ponta das Canas em pedra e cal, no extremo norte da Itha, visando à proteção da fabrica de óleo de baleia. Essa bateria nunca chegou a ser concluida, provavelmente, em função da decadência das 'feitorias meridionais' como as de São Sebastião e Bertioga. Dessa fortificação, restaram poucos vestígios. (MORI, 2003). No século XIX, com o aumento da produção de açúcar e aguardente, a economia local fortaleceu-se e a proteção do Porto de São Sebastião passou a ser prioridade para o governador instalado no Rio de Janeiro. Em 1820 o governador militar e major Maximiliano Augusto Penido construiu alguns fortes. O forte Sepetuba, situado na terra firme, com três canhöes, em frente a elle, ao norte da ilha do forte do Rabo-Azedo com quatro canhöes; o qual tendo uma fraca guarnição resisteo em 18 de novembro de 1826 um ataque do almirante Brown com corveta sarandy e um brigue, obrigando-o retirar-se no centro da Babia: o forte da Cruz na terra firme com dois canhöes; e o fronteiro a este, na ilha, o forte de villa bela com sete canhöes, na barra sul, o forte do Araça, na terra firme, com seis pecas; na ilha formando systema com elle, o forte da Feiticeira, armado com três canhões. Além destes, houve ainda no norte da ilha e fora da barra, o forte da Ponta das Canas, destinado conter 18 bocas de fogos - não foi concluido. (IHGEB, 1885). A simplicidade da construção destas pequenas fortificações de faxina (construção de madeira e terra semicircular) não resistiu ao abandono e com a chegada da ferrovia à Santos muitas desapareceram no tempo e no espaço; assim, as únicas construções fortificadas projetadas e construídas no século XIX em São Paulo permanecem somente na memória e carecem de estudos sistemáticos. Em São Sebastião e Ilhabela só foi possível encontrar alguns canhões de defesa das vilas que materializavam esta forte presença defensiva dos objetivos colonizadores lusitanos.

Em Bertioga encontrei o Forte São João que data do primeiro século em que existiu alguma feitoria defensiva, construção essa que será detalhadamente apresentada no texto. 
Ainda para fortalecer a defesa da entrada da Barra Pequena do Porto de Santos, cruzando fogo ${ }^{1}$ com o Forte São João, porém em solo da cidade do Guarujá - mais especificamente na Ilha de Santo Amaro - registrei ruínas do Forte São Felipe e São Luiz da Bertioga. O Forte São Luiz da Bertioga, apesar de nunca ter sido acabado, foi construído com o intuito de auxiliar o Forte São João, pois em 1769 um maremoto destruiu parte de sua cortina ${ }^{2}$ necessitando substituir a bateria ${ }^{3}$ avariada. Já o Forte São Felipe recebeu esta denominação em 1557, com a construção de "casa de pedra" ou "casa forte" pelo Capitão-mor Jorge Ferreira no local definido por Martim Afonso para a construção da fortificação. O lugar também foi morada de Hans Staden. Com o abandono no século XVII, foi recuperado pela Armação de Baleia a partir de 1745 e as ruínas subsistem e foram fotografadas na margem do Canal.

No outro extremo da Ilha de Santo Amaro temos a Fortaleza de Santo Amaro da Barra Grande, sendo apresentada detalhadamente junto ao Forte São João, Forte dos Andradas e ruínas do Fortim do Góes.

De acordo com os relatos dos guias locais, a parceria acontecia da seguinte forma: o Fortim do Góes caso avistasse algum navio invasor sinalizava para o Forte Augusto, que cruzava fogo com a Fortaleza da Barra, dava dois tiros de canhões avisando sobre os inimigos à vista ou um possível ataque; a Fortaleza da Barra Grande respondia com dois tiros e o barulho era ouvido em Itanhaem que envivam mensageiros a cavalo até São Paulo, solicitando reforços para os ataques que estavam sofrendo na entrada do canal de Santos.

Apesar de ter sido uma importante praça de guerra, o Forte Augusto transformou-se em ruínas mesmo localizado em um ponto privilegiado à beira mar. No local foi construída a Escola de Aprendizes dos Marinheiros do Estado de São Paulo, e mais tarde transformou-se em Escola e Instituto de Pesca e hoje Museu.

Para finalizar esse levantamento, o Forte dos Andradas - Guarujá - e a Fortaleza de Itaipu - Praia Grande - configuram as construções modernas e que foram planejadas de acordo com as modificações tecnológicas da época. A segunda metade do século XIX é marcada por profundas mudanças tecnológicas, militares, políticas, sociais e culturais abrindo muitos caminhos para o comércio e para a industrialização.

Até mesmo os estilos artísticos do ecletismo europeu aportaram em Santos e espalharam-se pelo Estado através das linhas férreas. As vilas coloniais do planalto edificadas em taipa de pilão e as do litoral em pedra e cal foram reconstruídas em tijolos em conformidade ao novo gosto internacional. (MORI, 2003).

\footnotetext{
${ }^{1}$ Cruzar fogo é um termo utilizado na estratégia defensiva, quando duas fortalezas, emparelhadas ou não, têm a capacidade de ataque cruzado entre dois pontos.

${ }^{2}$ Cortina: designação das muralhas na construção de fortificações.

${ }^{3}$ Bateria: armamentos instalados na cortina, como os canhões.
} 
Tendo em vista estas modificações, constata-se que as fortificações colniais já não supriam as necessidades defensivas da época. Assim, em 1896 iniciava-se o Projto de Defesa do Porto de Santos que iria substituir o já ultrapassado sistema de fortificações dos séculos anteriores. A moderna artilharia de alma raiada com alcance e precisão de até $10 \mathrm{~km}$ exigia um novo sistema de proteção em substituição ao modelo concebido no período colonial. $O$ projeto inicial terminado em 1898 criava duas linhas de defesa. A primeira protegeria a entrada da Baia de Santos de modo a evitar o bloqueio marítimo e a segunda linha ou barreira defenderia a barra de acesso do Porto. (MORI, 2003).

O projeto organizado pelo Capitão do Estado Maior Erico Augusto de Oliveira foi apresentado ao Ministério da Guerra, mas por se tratar de uma proposta cara e sofisticada somente a Fortaleza de Itaipu - considerando seu ponto estratégico - pode ser construída. Em 1902 iniciou-se a construção do sistema de defesa concentrado no mesmo sítio, composto de variadas baterias de artilharia com o Forte de Caxias, Forte da Ponta de Jurubatuba e o Forte Rego Barros, além da bateria de obuseiros ${ }^{4}$ no alto e a bateria Gomes Carneiro. Hoje somente o Forte Duque de Caxias está aberto para a visitação; os outros dois Fortes estão passando por um processo de restauração executado a partir de um projeto elaborado para o complexo que visa o turismo ecológico e cultural, já que a Fortaleza fica numa área de preservação natural.

A modernização da artilharia se fez necessário pelos avanços que a nação estava enfrentando, porém fica claro que, mesmo com a nova configuração defensiva que as fortificações vão assumindo os resquícios de elementos estilísticos de outras épocas, como os "merlões" vivem.

Antes da Segunda Guerra Mundial, a construção do Forte dos Andradas foi designada para a proteção do Porto de Santos, dando continuidade ao projeto de defesa elaborado, localizando-se estrategicamente na Ponta do Monduba na Ilha de Santo Amaro, no Guarujá, para cruzar fogo com a Fortaleza de Itaipu. Foi projetado pelo Tenente Cel. de Engenharia João Luiz Monteiro de Barros em 1934, mas sua construção se deu somente em 1938 e sua conclusão em 1942. A fortificação é subterrânea, escavada na rocha, com 380 m de comprimento e com cimento queimado. $\mathrm{Na}$ sua planta em forma de ' $\mathrm{T}$ ' são encontradas estruturas para o desenvolvimento das atividades diárias dos soldados que serviam neste Forte. Como a sala do comandante, dormitórios, banheiros, enfermeiras, cozinha, paiol - onde se guardava a munição - e esta era transportada com o auxílio de um elevador que lêvava até o topo da montanha onde se encontravam os canhões de procedência

\footnotetext{
${ }^{4}$ Obuseiros: diz-se de canhões que podem atirar projéteis ocos.

${ }^{5}$ Merlões: consistem em recortes, intervalos dentados nas ameias de uma fortaleza; aterros ou valas separadas por pequenas paredes, que caracterizam os sistemas defensivos dos castelos no século XV.
} 
alemã. Com todo esse aperfeiçoamento e com as preocupações voltadas para a evolução da artilharia mais eficaz e poderosa, o sentido funcional das imensas cortinas que materializam o sistema defensivo das fortificações, principalmente os castelos da Idade Média, perde a razão da existência dentro das novas estratégias. Desta forma o Forte dos Andradas e a Fortaleza de Itaipu foram as duas últimas construções fortificadas edificadas no país.

Assim resta-nos compreender e respeitar estes monumentos como marcos para a transmissão dos conhecimentos europeus bem como sinalizadores da construção de uma identidade nacional.

\title{
Forte São João e Fortaleza de Santo Amaro da Barra Grande
}

\begin{abstract}
"A arquitetura oficial no Brasil reflete a cada etapa da vida colonial as preocupações da coroa com sua sobrevivência como potência colonizadora. A preocupação com a defesa é uma constante revelada já no primeiro século com a construção de fortins e estacadas ao longo do litoral". (ZANINI, 1983).
\end{abstract}

A primeira construção fortificada sob o domínio lusitano em nosso país (1532), o Forte São João em Bertioga - S.P. registra claramente estas transições tecnológicas e estratégicas que as construções fortificadas sofrem ao longo dos anos. "Não obstante as inumeras interpretações históricas sobre a data e local da chegada da armada portuguesa em São Vicente, a escolha deste sitio para se levantar uma fortificação, não parecem aleatória ou desprovida de visão militar, pois durante os próximos 40 anos os grandes conflitos entre os colonizadores e os indigenas contrários tiveram como palco o Canal de Bertioga”. (MORI, 2003: 102). O canal foi palco de muitos conflitos territoriais como, por exemplo, entre os indígenas do norte (maramomis e tamoios) e os do sul (guaianases e tupiniquins).

O início da construção deste monumento é marcado pelas paliçadas cercado formado por um conjunto de estacadas de madeira, firmemente fincadas no chão, próximas umas das outras e unidas entre si, de modo a formarem um muro de proteção - conforme os ditames da neurobalística (ciência que estuda a impulsão de projéteis, por meio da força elástica, provocada pelo tensionamento ou torção de cordas) muito utilizada na Idade Média que se caracteriza pelos combates de curta distância onde a artilharia funcionava impulsionada pela força mecânica, como no caso dos nativos que utilizavam arcos e flechas para se defenderem dos inimigos. Para este período podemos caracterizá-lo por "Era da Artilharia Mecânica". Já mais tarde, com o fracasso diante alguns combates, julga-se necessário à utilização de outras formas que auxiliem na defesa, passa-se então a utilizar meios mais eficazes dentro da artilharia como, por exemplo, o desenvolvimento da pirobalística (ciência que estuda a impulsão de projéteis através da explosão da pólvora) composta de canhões, bombardas (peça de artilharia dos séc. XIV e XV, de cano curto, mais largo que a culatra, que lançava projéteis de ferro ou pedra) e das construções de cortinas horizontais, não importando a altura das construções, pois o grande au- 
xiliar da defesa é a artilharia, diferente do propósito da cortina vertical na neurobalística que exigia grandes e fortes muralhas para garantir a defesa dos combatentes.

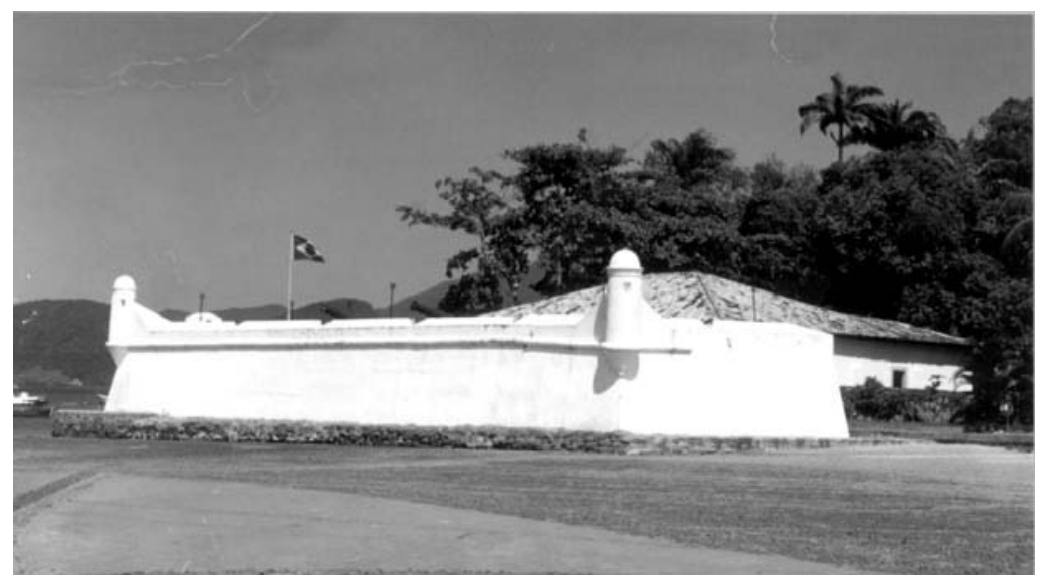

Em 22 de janeiro de 1532, chegando ao canal de Bertioga Martim Afonso - escolhido para fundar o primeiro núcleo lusitano em nossas terras - edificou uma torre para proteger e defender os portugueses dos possíveis ataques de invasores e até mesmo dos indígenas. "Não obstante as inúmeras interpretações históricas sobre a data e local da chegada da armada portuguesa em São Vicente, a escolha deste sitio para se levantar uma fortificação, não parece aleatória ou desprovida de visão militar, pois durante os próximos 40 anos os grandes conflitos entre os colonizadores e os indigenas contrários tiveram como palco o Canal de Bertioga". (MORI, 2003).

O canal foi palco de muitos conflitos territoriais como, por exemplo, entre os indígenas do norte (maramomis e tamoios) e os do sul (guaianases e tupiniquins). Martim então se aliou aos indígenas do sul por intermédio de João Ramalho, português que se casou com uma das filhas do cacique Tibiriçá, e fixou o único ponto fortificado nos primeiros anos em terras brasileiras. Essas tentativas como citado anteriormente mostram provisórias "cercas", "paliçadas" que os nativos utilizavam para se defender dos inimigos. "Eram obras defensivas com o fim exclusivo de proteção dentro dos princípios da neurobalistica afinal os indigenas encontravam-se na idade da pedra polida". (MORI, 2003).

Para este sistema de defesa tomamos como base os conflitos ocorridos na Idade Média, guerras de contato nos quais os combatentes tinham munição com pouco poder de destruição, desta forma a grande e importante aliada para a defesa seria a "cortina vertical", caracterizada por elevados castelos e torres, pois quanto maior a altura dos muros (cortinas) mais protegidos estaria os combatentes e os locais a serem defendidos. 
Portanto podemos caracterizar as paliçadas e as cercas pontiagudas que os indígenas construíam como fortificações provisórias, que se enquadram nos princípios da neurobalística, visto que os indígenas utilizavam munições impulsionadas pela força elástica como os arcos e flechas entre outros armamentos primitivos. Mesmo com as improvisações e a força dos indígenas, Martim percebeu que seria pouco para segurar os inimigos: ao perder algumas batalhas solicitou reforços ao Rei, e se não fosse atendido a Coroa Portuguesa corria o risco de perder suas terras, com tamanha preocupação seu requerimento foi deferido em 25/06/1551 onde o Rei ordenou a construção da fortaleza, a primeira "Fortaleza Real" com projeto arquitetônico enviado de Portugal.

O Forte São João, o primeiro a ser construído no Brasil, segue os passos dos engenheiros lusitanos ou a serviço da Coroa que fundamentam suas produções de acordo com o Renascimento que estava efervescente na Europa. A busca por um ideal de beleza baseava-se na lei das proporções geométricas, elaboradas e desenvolvidas por meio dos tratados de Alberti (Da Arquitectura, 1454); Sebastião Serlio (L'Architettura, 1540); Jacopo Barozzi Vignola (Regole delli cinque ordini, 1552); Andrea Palladio (Quatro libri dell'architettura, 1562). O modelo envidado pelo Rei para a edificação de uma 'Fortaleza Real' sofreu algumas alterações para atender as necessidades locais, pois se baseava nos conceitos renascentistas e no desenvolvimento da pirobalística não favorecendo a aliança com os indígenas, pois eles desconheciam os ditames. Fez-se necessário à construção de um forte que contemplasse as duas realidades. O Forte foi um modelo de transição onde os novos métodos de defesa para as armas dos franceses: as cortinas horizontais com suas respectivas canhoneiras para os ataques com a artilharia enviada para guarnecer o local, e as cercas paliçadas para as flechas dos tamoios. Desta forma, a aliança dos nativos com os colonizadores tornou-se funcional na elaboração prática de um mesmo cenário.

Edificada em pedra de cantaria aparente com sambaqui 6 , óleo de baleia e areia, é o que conhecemos como argamassa na construção civil, o Forte é composto por um baluarte ${ }^{7}$ de pedra com uma 'cortina horizontal' onde se encontrava a praça das armas - local onde a atividades militares eram realizadas - com cinco canhoneiras $^{8}$ e também servia como espaço de vigilância com o auxílio de duas guaritas $^{9}$ nos seus vértices. Nas guaritas seteiras ${ }^{10}$ serviam para a observação do

\footnotetext{
${ }^{6}$ Depósito pré-histórico de conchas; resíduos marinhos.

7 Volumoso banco de terra que permitia incluir na fortaleza um local de vigilância. Era freqüentemente revestido de pedra, servindo como toda a muralha.

${ }^{8}$ Espaço aberto no parapeito voltado para dentro ou para fora onde a artilharia é disparada.

${ }^{9}$ Pequena torre de tiro suspensa na parede externa de uma torre, normalmente em uma quina ou próximo a uma entrada.

${ }^{10}$ Abertura na parede da guarita ou da fortificação para o lançamento de mísseis, observação e/ou ventilação.
} 
canal possibilitando sinalizar discretamente e rapidamente a presença de inimigos, entre a plataforma (praça das armas) e o quartel há um espaço pelo qual era destinada a área de concentração dos soldados. Após essa área ficava o quartel do General composto pela sua sala, o quarto oficial, sala de reuniões, refeitório e um cômodo onde os soldados dormiam no chão, além de um mezanino onde ficavam as munições. As paredes do quartel são tão espessas quanto à da cortina, as janelas e as portas soa de madeira e o ambiente não possuía forro, o qual foi acrescentado com a restauração; as telhas eram fabricadas nas coxas das escravas - formato semicircular. A pequena fortaleza foi aperfeiçoada entre 1551 e 1560, e em 1750 praticamente reconstruída.

A historicidade de suas exuberantes formas não só afirmam a funcionalidade da construção, mas também evoca os significados ideológicos do pensamento deste período para a História da Arte.

Foi tombado pelo IPHAN (Instituto do Patrimônio Histórico e Artístico Nacional) em 31/03/1965 e como principal combatente do litoral norte, o quartel virou museu com salas ambientalizadas com cenas cotidianas dos indígenas, peças da artilharia, réplica das armaduras portuguesas entre outros móveis e pinturas. A organização do museu procura contemplar e transmitir de forma clara esses conhecimentos históricos e artísticos conforme as imagens que foram registradas no local.

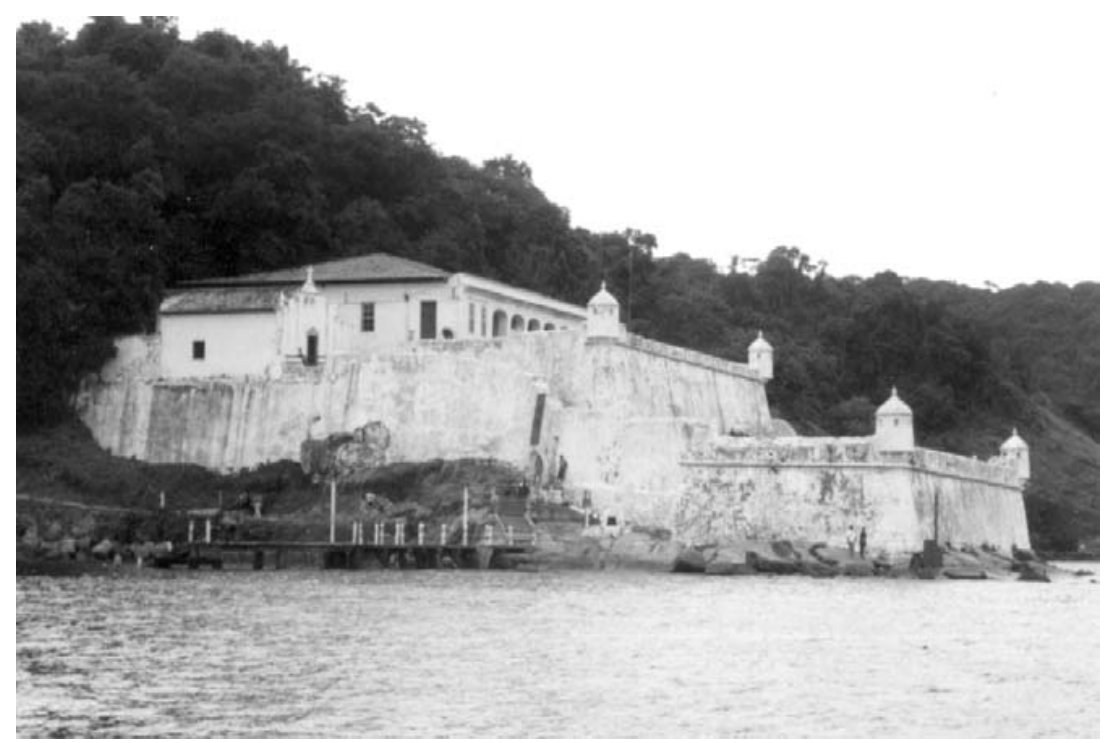


Já a Fortaleza da Barra Grande foi erguida estrategicamente em 1584 durante o domínio Espanhol sobre Portugal para defender o Porto de Santos juntamente com o Forte São João - Bertioga - na entrada pequena do canal. "A construção dessa fortaleza tinha dois objetivos. O primeiro seria de guarnecer o Porto de Santos, um entreposto importante para a rota ao Estreito de Magalhães, de navegantes ingleses e bolandeses; e o segundo, marcar simbolicamente a presensa do rei Felipe II da Espanha (Felipe I de Portugal) nessas paragens perdidas do Atlântico Sul, impondo aos vicentinos a obediência legal à dinastia dos Habsburgos". (MORI, 2003)

Giovanni Batista Antonelli, engenheiro militar responsável pela construção da Fortaleza da Barra Grande, foi o mias importante e o primeiro projetista a serviço de Felipe II nas Américas de modo especial na Capitania de São Vicente onde inúmeros de seus artífices permanecem influenciados por uma vasta experiência nas vilas da renascença na Itália e dos tratados italianos - berço do Renascimento.

Considerando que a Fortaleza passou por várias reestruturações no século XVII e XVIII, com a restauração do trono português e da descoberta do ouro, que o sistema defensivo passa a ser prioridade da Coroa e com o auxílio do brigadeiro João Massé a Fortaleza sofreu algumas transformações. As primitivas construções seriam substituídas por um complexo sistema a partir de 1714. Entre as modificações as mais significativas foram a transformação da casa da pólvora em capela dedicada ao padroeiro Santo Amaro e a construção de um paiol no topo do esporão rochoso para atender as melhores condições de armazenamento.

Mesmo com as modificações a Fortaleza tem uma característica diferenciada, suas muralhas acompanham a topografia do local uma pratica até então desligada dos princípios da tipologia das fortificações baseadas nas leis proporcionais renascentistas.

Já o quartel, onde eram executadas as atividades militares diárias, é similar ao projetado no Forte São João que se apóia nas formas geométricas e proporcionais como estrutura ativa e funcional da construção. A essa miscigenação de procedimentos deve-se a característica das construções fortificadas que Antonelli projetou em outras regiões do mundo baseadas nas escalas naturais que o local podia oferecer.

O sistema defensivo da Fortaleza é composto por uma cortina vertical com duas baterias sobrepostas $(C)$ sendo que uma acompanha a muralha (A) e a outra se restringe à praça das armas em frente ao quartel (D) e nos seus vértices possuem guaritas (B) com seteiras. A técnica de construção é a de argamassa de sambaqui com pedra de cantaria aparente. $\mathrm{O}$ quartel possui paredes espessas, janelas pequenas, baixas e de madeira. Ao lado do quartel está a antiga casa da pólvora, transformada em capela, em $1742 \mathrm{com}$ um frontão com voluta (E) dedicada ao padroeiro; no topo do esporão rochoso se localiza o paiol (F) construído para atender melhor as necessidades físicas das munições. No final da 
muralha fica o portão espanhol $(G)$ que se diferencia por ter um outro portão suspenso que servia como abafa defendendo a construção de possíveis invasores por terra. A Fortaleza possui um diferencial na sua tipologia; a assimetria da muralha se caracteriza exclusivamente com a topografia local.

A Fortaleza da Barra Grande foi tombada pelo Iphan em 23/04/1964 e é mantida pela Unisantos (Universidade Católica de Santos) e pela prefeitura municipal do Guarujá, os guias que acompanham os visitantes são treinados por uma equipe da Universidade.

A trajetória das construções no Estado de São Paulo demonstra cronológicamente os desdobramentos que os sistemas defensivos vão assumindo ao longo dos anos. Com imenso privilégio e prazer tive contatos desde as Fortificações coloniais as do século XX, uma viagem no tempo e espaço de um país tão miscigenado.

\section{Bibliografia e demais fontes}

1. ALBERNAZ, Maria Paula. Dicionário Ilustrado de Arquitetura. São Paulo: Pro-Editores, 2000. 670 p.il. $2^{\circ} \mathrm{ed}$.

2. ARGAN, G. C. História da arte como história da cidade. São Paulo: Martins Fontes, 1995.

3. BELLUZZO, Ana Maria de Moraes. O Brasil dos viajantes. Faculdade de Arquitetura e Urbanismo, Universidade de São Paulo, São Paulo: Metavideo, 1994.

4. BUENO, Eduardo. Brasil: uma História. São Paulo: Ática, 2003.

5. CAMPELLO, Glauco. Patrimônio e Cidade, Cidade e Patrimônio. In: Revista do Patrimônio e Artístico Nacional, no 24.

6. CANCLINI, Nestor Garcia. O Patrimônio Cultural e a Construção Imaginária do Nacional. In: Revista do Patrimônio e Artístico Nacional, $\mathrm{n}^{\circ} 22$.

7. COELHO, Teixeira. Dicionário Crítico de Política Cultural. Cultura e Imaginário. São Paulo: Iluminuras, 1997.

8. CUNHA, Maria Clementina Pereira. Patrimônio Histórico e Cidadania: uma discussão necessária. In: O Direito a Memória: patrimônio histórico e cidadania. São Paulo: SMC/DPH, 1992, 9-11.

9.DE DECCA, Edgar S. Memória e Cidadania. In: O Direito a Memória: patrimônio histórico e cidadania. São Paulo: SMC/DPH, 1992, 129-136

10. DUCHER, Robert. Características dos Estilos. São Paulo: Martins Fontes, 2001.

11. DURHAM, E. R. Produzindo o passado: estratégias de construção do patrimônio cultural. São Paulo: Brasiliense, 1984.

12. FENELON, Déa Ribeiro. Politicas Culturais e Patrimônio Histórico. In: O Direito à Memória: patrimônio histórico e cidadania. São Paulo: SMC/DPH, 1992. 29-36.

13. FUNARI, P.P. A hermenêutica das ciências humanas: a historia e a teoria e práxis arqueológicas. R. da SBPC. Curitiba: 10,39,1995 .

14. - Os desafios da destruicão e conservação do Patrimônio Cultural no Brasil, Trabalhos de Antropologia e Etnologia, Porto, 41, 1/2, 2001, 23-32.

15. FERREIRA, Lucio Menezes; FUNARI, Pedro Paulo. Cultura Material, Histórica e Patrimônio. IFCH/UNICAMP: Campinas, 2003.

16. GONÇALVES, José Reinaldo. Autenticidade, memória e ideologias nacionais: o problema dos patrimônios culturais. In: Estudos Históricos. V.1 - n 2, Rio de Janeiro: UFRJ, 1988, 267-275.

17. FRONER. Y. A. Os domínios da memória - um estudo sobre a construção do pensamento preservacionista nos campi da Museologia, Arqueologia e Ciência da Conservação. 2001. 419 f. Tese de Doutorado. Faculdade de Filosofia, Letras e Ciências Humanas, Universidade de São Paulo, São Paulo. 2001.

18. GOULART, Lairton Gomes. Bertioga. Berço da história do Brasil. Bertioga: Garilli, 2002.

19. LEACH, Edmund. Cultura/Culturas. In: Einaudi 1: Memória/Historia. Portugal: Imp. Nacional Casa da Moeda, $1984,102-135$.

20. MICHEL, G. As cidades históricas - Formas de vida do passado que ainda subsitem. O correio. Natureza e Cultura. Um patrimônio para todos. Rio de Janeiro: ano 16, nº 10, p. 16-26, out. 1988. 
21. MORI, Victor Hugo. Arquitetura Militar. Um panorama histórico a partir do Porto de Santos. São Paulo: Imprensa Oficial, 2003.

22. PIRES, Mario Jorge. Lazer e Turismo Cultural. São Paulo: Manole, 2002.

23. SANTOS, Cecilia Rodrigues dos. Novas fronteiras e pactos para o patrimônio cultural. São Paulo: perspectiva, v. 15, n. 2, abr. /jun.2001.

24. SECOMANDI, Elcio Rogério. Fortaleza de Santo Amaro da Barra Grande. Santos: Leopoldianum.

25. SILVA, F.F. Fortificações Brasileiras: maquina de guerra e de memória. 1991. 265 f. Tese de Doutorado Faculdade de Filosofia, Letras e Ciências Humanas, Departamento de Historia, Universidade de São Paulo, São Paulo: 1991.

26. SUMMERSON, John. A linguagem clássica da arquitetura. São Paulo: Martins Fontes, 1997.

27. ZANINI, W. História geral da arte no Brasil. Vol. I. São Paulo: Instituto Walther Moreira Salles, 1983.

Adriana Sanajoti Nakamuta. Graduação em Artes Plásticas pela Universidade Federal de Uberlândia; bolsista do PIBIC/CNPq durante os anos de 2003 e 2004; pesquisadora do NUPAV (Núcleo de Pesquisas em Artes Visuais DEART/UFU); anakamuta@yahoo.com.br. 